\title{
The Use of a Service Modeler Together with a PLM Software for the Management of Product-Related Services: A First Use-case-based Approach to Configure Service Components for Product-Related Services
}

\author{
Christian Zinke, Kyrill Meyer, Florian Golemo, and Lars-Peter Meyer \\ University Leipzig \\ zinke@informatik.uni-leipzig.de
}

\begin{abstract}
For most goods-producing companies the provision of productrelated services is already a necessary commodity (Wildemann 2009). Such services are regarded as necessary attachment to a successful production of goods by most companies. To manage products and services, companies rely on different methods and tools that span the entire lifecycle (Sendler 2009). With the goal of raising efficiency and quality at affordable costs, those methods and tools are implemented or supported with the help of information systems such as PLM/PDM solutions. In this context, it is observed that the development and management of services, even though, they increasingly become a vital part for many companies, is neglected. Furthermore a systematic, tool-supported approach using the existing PLM/PDM-systems can be seen as problem area (Blinn et al. 2009).

The objective of our paper is to minimize problems with product related services such as fitting cost estimation, matters of quality control and communication inhouse or with the customer. Therefore, existing management approaches of service engineering (Ganz et al. 2010) need to find their implementation within PLM/PDM systems in a way, that product related services can be handled throughout the lifecycle and interrelationships between product and service (e.g. a maintenance service for a certain sold machine) can be accounted for. Our scope is the establishment of a Service Lifecycle Management for product related services. Our work is based on case study work conducted in the field of engineering that supports the problem and objective. Therefore, as results we can show the validated problem field and exemplary demonstrate with the help of the ARAS Innovator PLM solution (Aras Corporation 2012) and the Service Modeller (Klingner et al. 2011) how product related services can be developed and managed by using a service lifecycle PLM tool. The example focusses especially on the configuration of service components and how service instances can be connected to product data.
\end{abstract}

\section{$1 \quad$ Objective and Domain}

To manage material goods producers use methods and tools which can be summarized in its entirety as a Product-Lifecycle-Management (Sendler 2009). They 
normally include ways to manage ressources, processes and data (such as e.g. CAD). The aim is to ensure a systematic approach to reach a higheffectiveness, guarantee the quality of products and ultimately safeguard the competitiveness and profitability of the entire company.

As part of the onging developments in the markets one can recognize an upgrowing interest in product-related services during the recent years (Stille 2003). High business competition, globalization and a decreasing time-to-market present itself as a difficult situation for good-producing companies (Bruhn, Hadwich 2006). In this, product-related services become more and more a unique selling proposition (Blinn et al. 2009). At the same time it has been recognized that the support for services during the lifecycle is not at the same level as it is for material goods (Ganz et al. 2010). Even though in order to guarantee a high-quality service it is necessary to use different management methods and tools (for services). Such methods and tools are the objective of the Services Science and Service Engineering (Böttcher et al. 2011). By neglecting already existing management methods and standardized procedures (Bullinger 2006; Corsten 2007), such as provided by the Service Engineering, companies do not exploit their full potential and provide their services inefficiently in a way that may result in damage of their own interests. A systematic approach and active management (planning, monitoring and controlling) of services provides a better understanding of the benefits of solutions offered, the marketing opportunities, an adherence to quality standards and gives the ability to increase the efficiency and reduce costs (Klingner et al. 2011). A holistic and overall method to manage services is the Service-Lifecycle-Management (SLM) (Ap Verlag 2012). The SLM approach combines different management methods and tools, based on a lifecycle view. In Science and Economy, this approach is only used and explored for pure (IT-) service providers (Orr 2011) so far. The motivation of this paper is to transfer knowledge to a more general SLM approach that can also be used in other domains. We demonstrate the feasabilty in the areas of product-related services (Vargo 2011).

The paper, the approach and the use-cases are based on a qualitative study in the domain of special machinery. This domain is technology intensive, highly interactive (on the side to the customer) and very constumer specific. The following solution will show the theoretical and practical integration of a SLM and PLM/PDM system, so that product-related services can be handled throughout the lifecycle and interrelationships between product and service (e.g. a maintenance service for a certain sold machine) can be accounted for.

Therefore, we first present an integrated PSLM (product-service-lifecycle management) approach as the scientific basis for the use-case based integration of a SLM Tool (“Service Modeller”) in a PLM/PDM System (Aras Innovator).

\section{Scope and Technology}

The scope of this paper is to establish a Service Lifecycle Management for product related services. Firstly, there is a need to describe functions that will be necessary for Service Engineering and Management. Secondly, it is neccessary to describe how 
these functions can be integrated with PLM/PDM solutions to form a holistic support system. First of all, we describe the Service Lifecycle Management and how we can combine PLM approaches mainly focusing on material goods.

\subsection{Service and Product Lifecycle Management}

A Service Lifecycle Management is a holistic management approach, which combines different methods and tools for managing services over its lifecycle. These methods are: service portfolio management, service strategy, idea management, service level management, quality management, process management, configuration management, resource management, supply chain management and customer management (see Fig. 1).

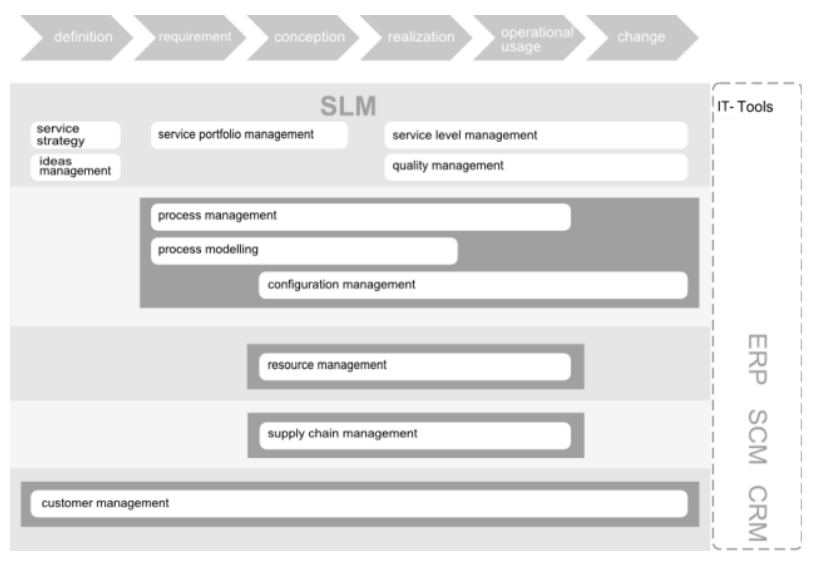

Fig. 1. SLM Methods and Tools (Meyer, 2012)

This lifecycle management approach for services will have to be used for any service delivered in relationship to a certain product. This is our theoretical framework to integrate a Service Lifecycle Management for product-related services. Combined with practical studies we identified some basic core functions for an IT-based support of these methods.

While a number of necessary functions could be identified, yet as part of this paper we will focus our discussion on the following: (F1) management of portfolio information, which means the managing of services, service components, products and product components and their access to information. Other functions identified are:

- F2: Creation and management of workflows and processes for services and service components

- F3: Management and assignment of the resources to be provided for the service and its service level

- F4: Management of customers - as contractors and access to relevant information for product and services 
- F5: Managing knowledge that is formed in the processes about the whole service and access to the information during the performance

- F6: Management of departments and suppliers during the implementation and modification of products and services

- F7: Measurement and recording of parameters of individual services

- F8: Reporting

- F9: Managing Customer Feedback

- F10: Managing the lifecycle of services and possibilities for change of the parameters and components

The focused function F1 has some subfunctions, which are:

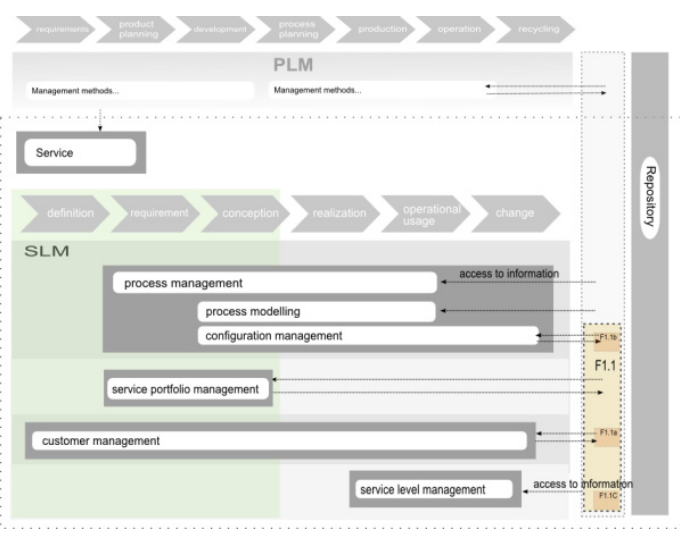

Fig. 2. Functions F1 and supported management approach

- F1.1a: Provision of services and product catalog for the customer

- F1.1b: General management of the configuration options of the service modules and the configuration selected by the customer

The management of portfolio information for services is not supported in standard PLM/PDM systems (see Fig. 2). These systems mostly focus on Bill of Material (BOM) and CAD integration. To support the portfolio and configuration management we can use the "Service Modeller". This tool and the chosen PLM/PDM system will be presented next.

\subsection{Used Technology and Tools}

\subsubsection{Description of the Product-Lifecycle Management Tool}

For our prototype solution we used the Aras Innovator, a freely available PLM system developed by the Aras Corporation (Aras Corporation 2012a). The selection of this solution is the result of a comparison of different free PLM systems, but stands as an example for any other software available in this context. The Aras PLM system consists of several open source modules build on top of the closed source Aras Enterprise 
Application Framework. A major factor (A significant aspect or key factor) for our choice was the highly flexible data model and the implementation of the SOAPInterface (Aras Corporation 2012b).

\subsubsection{Description of the Service Modeller}

The Service Modeller is a tool, which has been prototyped and developed at the Business Information Systems chair at the University of Leipzig. It helps with the component tree based modeling and management of complex services and service portfolios. For each service component key performance indicators can be defined and stored, which can either be dynamically calculated formulas or fixed values. In addition to that, nonfunctional attributes can be defined. While the dynamic key performance indicators helps by the evaluation of services, the nonfunctional attributes can be used for filtering or further descriptions. Finally, cardinality restrictions on the tree connectors can be used to model constraints for the component combinations (Klingner et al. 2011).

\section{$3 \quad$ Results}

\subsection{Use Case}

Our descriptions are based on case study work conducted in the field of engineering that supports the problem and objective. Thes use-case focuses on the configuration of service components and how service instances can be connected to the product data. Hereinafter a simplified example is outlined to illustrate the interaction between product and service configuration (see fig. 3).

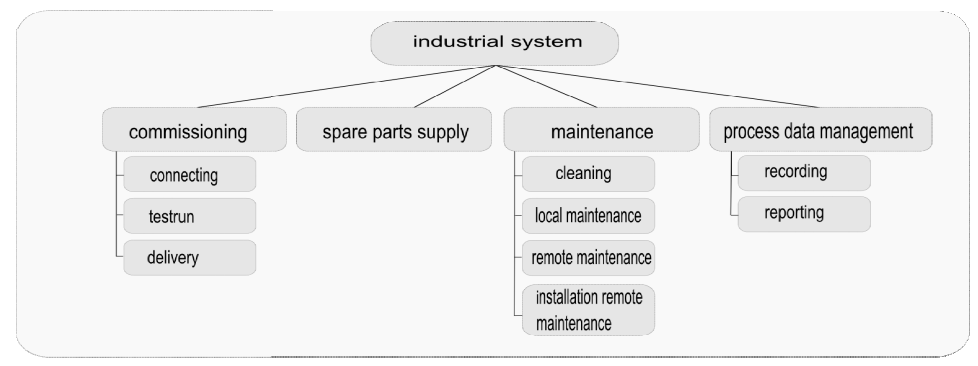

Fig. 3. (After-sales) service components

In this case, an abstract industrial system is used. For this industrial system the producer provides some (after-sales) services. In a nutshell, they can be described as: commission, spare parts supply, maintenance and process data management. To manage these services and to make it transparent for the customer, it is necessary to use a service portfolio management. This means, that single services get divided into different service components which can be managed later. The components in which the service is devided are: local maintenance, remote maintenance, cleaning and the installation of a remote maintenance. Some of the services are optional, such as the remote maintenance or the delivery. That means the service is only delivered if the 
customer chooses it or a component may be technically necessary. The service commissioning is divided into the components delivery, connecting (electricity or some remote connections) and test run (to test the complex system). The process data management is separated in two components: recording and reporting. Here, we see the dependency between material good and other services: a reporting service needs to store information, and this information can only be stored if the material good has components (such as sensors) to measure this information. As an overview this shows how services can be modularized and how these modules can be sold customer specific.

Many of these services cannot be regarded independently of the industrial system to which they relate. Thus, there are numerous links to various components of the system itself. To understand the correlation, it is necessary to know the product portfolio. The product data is stored in the PLM/PDM system. There we find a Bill of Material, installation layouts and technical documentations for each sold product. In our case, the Aras Innovator can store all data. Product-configuration can be done with the help of the PLM/PDM and calculations conducted afterwards, such e.g. the price and delivery time.

Certain dependencies between product components and service components will remain. Thus, in the presented case, a remote service will only be provided if the component LAN was installed. Beyond such direct dependencies, a recommender engine may hint to other helpful components. On assembly of an industrial system, the services "connection" and "test run" may be recommended to ensure a consistent performance of the system. If the customer opts for on-site maintenance (local maintenance), the vendor should recommend the product component LAN for diagnostics to lower costs for the maintenance service. If such product-service relationship is not considered as part of the design phase, it may become difficult or impossible to offer an integrated solution in the end. Our tool will help to identify relationships and manage the necessary data exchange.

This shows that already on the portfolio level many links between products and services exist. Consequently, a holistic view, offered through a supporting IT-system is crucial. Through the combination of the management tools it becomes possible to detect inconsistencies in the configuration of the services provided at an early stage.

\subsection{Interface Description of the Used Tools}

The Aras Innovator requires a Microsoft windows server with installed Internet Information Services (IIS). On the client side it utilizes an ActiveX component which requires the use of the Microsoft Internet Explorer. Core components of the Aras Innovator can be modified or extended by editing $\mathrm{C} \#$ or visual basic code in the browser. The frontend modification is possible with primarily JavaScript.

As interface the Aras Innovator supports SOAP and a special .NET/COM library called IOM-API. According to the documentation both interfaces support the same functionality, the IOM is just a convenient method to handle the SOAP requests. Which data and methods are available via SOAP can be configured at the frontend. 
The Service Modeller offers a SOAP interface as well and supports the retrieval of service models or service configurations. This is a static interface, thus, any modifications need programming effort. This is an important difference to the Aras Innovator.

\subsection{Implementation Concept}

For the integration of the service models into the PLM system we need to retrieve them from the Service Modeller and create a copy in the Aras Innovator. Furthermore, we want to facilitate the coupling of product data to services and the collection of data from specific products and service contracts.

This goal is achieved by the use of a converter. The converter enables the use of existing interfaces of both systems and can manage the data transfer. As mentioned above, the SOAP interface as well as the IOM interface would be possible with the Aras innovator. Our implementation utilizes the SOAP interfaces of the ServiceModeller and the Aras Innovator.

In this paper, we should distinguish between a product model and a product configuration. The product model contains all necessary or possible parts and configurations for a product. A product configuration is the specific configuration of a product as ordered by a specific customer. This is important, because in some scenarios the available services depend on the selection of product parts. As an example one may imagine an industrial system, delivered with an optional remote administration module. If the module is chosen by the customer, the producer may repair the system from afar. If not, an engineer has to travel there and do the maintenance manually. These services may be mapped analogously in the Service Modeller: There are service models, which define the possible services and service configurations, which select certain services from a model. Both data entities have to be saved, because depending on the product, different service models may be available, and depending on customer and product the service configuration may vary.

For the sake of integration it should be possible to connect this information. The design of the integration process is displayed in Fig. 4.

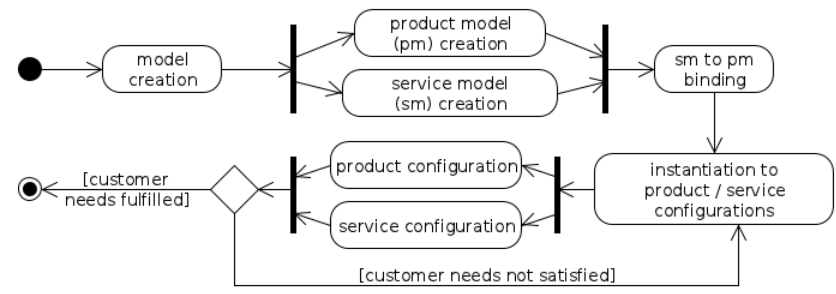

Fig. 4. The process of integration. Models are created in the Aras Innovator and in the Service Modeller independently of each other. For each product model the service models are chosen. The so created bundles may be offered to customers. As soon as a consumer is found, certain options of product and service get picked. If they are satisfying for all parties, they may be delivered. If not they must be respecified as product and service configurations. 


\subsection{Technical Realization}

The Aras Innovator already contains the item types "part" and "product". A part in the Innovator can either be a part or a setup of different parts. For example, the part "Ford Mustang GT" consists among others of the parts "wheel" (4 pcs.), "engine" and "chassis". A wheel may consist of "tire rubber", "rim" and "screw" (4 pcs.). The item type "product" is the equivalent of the product model. All available parts and options may be saved there. For example, in the product "Ford Mustang" there may be options for "Ford Mustang GT" and "Ford Mustang GT/CS", where the last one is a variation of the first.

For the implementation a counterpart of the product configuration is necessary. It should store which variants of a certain product have been choosen by a customer. Therefore, in Aras Innovator a new item type is introduced: product configuration. For each selected product model it saves the model and the chosen options.

In the Service Modeller the required item types already exist. To be able to map them onto the Innovator, they must be created there, too. Therefore, the item types "service model", "service configuration" and "service component" must be set up whereas the latter forms models and configurations. In order to refer to each other, the following new relationships are needed: model - component, configuration - component, component - component and model - configuration. These X-Y relationships correspond to the 1:n schema, i.e. "one $\mathrm{X}$ can have many $\mathrm{Y}$ ". To realize serviceproduct mapping, the relations explained in the previous chapter have to be included, too: product - service model, product configuration - service configuration. The corresponding data model is displayed in fig. 5 .

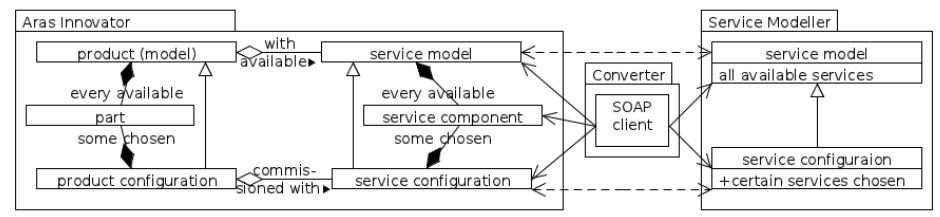

Fig. 5. Data model of the overall system of Aras Innovator, Converter and Service Modeller. The Converter accesses the SOAP-interfaces of both tools. It helps extracting service data from the Service Modeller and transforming it for Aras Innovator.

In the Aras Innovator new interfaces have to be set up for the new service item types and service relations, allowing for their creation out of other programs. As soon as these interfaces are ready, the converter may fetch the service models and configurations in certain intervals and transmit them. When this is done, the user is offered a possibility to integrate the service into the product lifecycle as described earlier.

\section{Conclusion and Further Work}

We have shown how product-oriented support systems (PLM/PDM) can be enriched with a service-oriented approach and its utility. The "Service Modeller" initially 
supports only a part of the Service Lifecycle Management, the portfolio management, mainly the componentization and configuration. In the presented scenario not only the components of service and product can be linked, but also external factors can be integrated.

We presented how an integrated service and product data management as basis of a SLM. Our demonstration is limited to the configuration and portolio managemen functions (F1). For other necessary functions it will also be required to identifiy tools and how they can interact with PLM/PDM systems.

\section{References}

Ap Verlag GmbH (2012), http: / /www . apverlag . de/OnlineArtikel / 20081112 / $20081112 \mathrm{~h} \% 20$ Siemens $\% 20$ Service $\% 20 \mathrm{Lifecycle} \% 20$ Management . htm . (accessed January 31, 2013)

Aras Corporation (2012a), http: / / www . aras . com (accessed July 24, 2012)

Aras Corporation Model-based SOA (2012b), http://www.aras.com/technology/ model-based-soa . aspx. (accessed July 24, 2012)

Blinn, N., et al.: Lebenszyklusmodelle hybrider Wertschöpfung. Modellimplikationen und Fallstudie. In: Thomas, O., Loos, P., Nüttgens, M. (eds.) Hybride Wertschöpfung: Mobile Anwendungssysteme für effiziente Dienstleistungsprozesse im Technischen Kundendienst. Springer, Heidelberg (2010)

Böttcher, M., Klingner, S.: Providing a Method for Composing Modular B2B-Services. Journal of Business and Industrial Marketing 26(5), S. 320-S. 331 (2011)

Bruhn, M., Hadwich, K.: Produkt- und Servicemanagement. Vahlen, München (2006)

Bullinger, H., Scheer, J.: Service Engineering - Entwicklung und Gestaltung innovativer Dienstleistungen. 2. Aufl. Springer (2006)

Corsten, H., Gössinger, R.: Dienstleistungsmanagement.5. Aufl, München, Wien Oldenburg (2007)

Ganz, W., Bienzeisler, B.: Management hybrider Wertschöpfung - Potenziale, Perspektiven und praxisorientierte Beispiele, Fraunhofer-IAO-, Stuttgart (2010)

Klingner, S., et al.: Managing complex service portfolios: A business case from a full service provider. In: Reser 2011 Proceedings, Hamburg (2011)

Meyer, K., et al.: Produkt-Dienstleistungs-Lebenszyklus: Methoden und Funktionen für die Entwicklung und das Management produktbegleitender Dienstleistungen. In: Meyer, K., Abdelkafi, N. (eds.) Smart Services and Service Science - Proceedings of the 4th International Symposium on Services Science. Leipziger Beiträge zur Informatik, Band 36, Leipzig (2012)

Orr, A.T.: Introductiontothe ITIL servicelifecycle, 3rd edn. TSO, London (2011)

Sendler, U.: Das PLM-Kompendium Referenzbuch des Produkt-Lebenszyklus-Managements. Springer, Heidelberg (2009)

Stille, F.: Produktbegleitende Dienstleistungen gewinnen weiter an Bedeutung. Wochenbericht des DIW Nr.21/2003, pp. 336-342 (2003)

Vargo, S., Lusch, R., Hobel, C., Wieland, H.: Alternative Logiken für Dienstleistungen: von hybriden Systemen zu Serviceökosystemen. In: Spath, D., Ganz, W. (eds.) Am Puls wirtschaftlicher Entwicklung - Dienstleistungstrends, pp. 137-153. Carl Hanser Verlag, München (2011)

Wildemann, H.: Produkte und Services entwickeln und managen: Strategien, Konzepte, Methoden, 2. Aufl. TCW Transfer-Centrum, München (2009) 